\title{
THE
}

$1-2018$

\section{User Wayfinding Strategies in Public Library Facilities}

Lauren $\mathrm{H}$. Mandel

University of Rhode Island, lauren_mandel@uri.edu

Kelly A. LeMeur

Roger Williams University

Follow this and additional works at: https://digitalcommons.uri.edu/lsc_facpubs

The University of Rhode Island Faculty have made this article openly available.

Please let us know how Open Access to this research benefits you.

This is a pre-publication author manuscript of the final, published article.

Terms of Use

This article is made available under the terms and conditions applicable towards Open Access

Policy Articles, as set forth in our Terms of Use.

Citation/Publisher Attribution

Mandel, Lauren $\mathrm{H}$. and Kelly A. LeMeur. "User wayfinding strategies in public library facilities." Library and Information Science Research, vol. 40, issue 1, January 2018. https://doi.org/10.1016/j.lisr.2018.04.001

This Article is brought to you for free and open access by the Graduate School of Library and Information Studies at DigitalCommons@URI. It has been accepted for inclusion in Graduate School of Library and Information Studies Faculty Publications by an authorized administrator of DigitalCommons@URI. For more information, please contact digitalcommons-group@uri.edu. 


\title{
User Wayfinding Strategies in Public Library Facilities
}

\author{
Lauren H. Mandel, PhD \\ Assistant Professor \\ University of Rhode Island
}

\author{
Kelly A. LeMeur \\ Learning Commons Librarian \\ Roger Williams University
}

\section{Preprint}

\begin{abstract}
An experiment in a public library demonstrates that Passini's conceptual framework of wayfinding can be applied to public library patron wayfinding behavior. Participants were asked to think aloud while completing prescribed wayfinding tasks. Findings indicate that library patrons use all five of Passini's strategies to varying degrees, supporting the need for further research testing this framework with library patrons. Participants were given varying level of details on Passini's strategies prior to completing the wayfinding tasks, and that intervention had no significant effect on the results.

\section{Introduction}

On the whole, wayfinding research in LIS has been largely practical and not based on theories of wayfinding behavior. A study guided by Passini's conceptual framework of wayfinding (Mandel, 2013) was inconclusive due to methodological limitations. Passini's framework (1981) includes five strategies of wayfinding: 1) dividing the task into manageable parts while keeping an eye on the larger task at hand, 2) narrowing, 3) adapting and responding, 4) accessing one's schemata, and 5) gathering information and adapting accordingly. Strategy 1 is a structured process that operates at different levels of generality, through which the wayfinder focuses on individual tasks or subtasks always while considering the problem as a whole. Strategy 2 is how the wayfinder deals with one problem or subtask at a time. In using strategy 3 , the wayfinder follows a continuous process of adapting and responding to environmental cues in order to deal with unforeseen problems whenever they occur. With strategy 4 , the wayfinder relies on an existing solution repertoire for as large a part of the decision plan as possible. Using strategy 5 , the wayfinder bases his plan on gathering and responding to available environmental information.
\end{abstract}


While some observed behaviors from the previous study (Mandel, 2013) fit into the framework of these five strategies, others did not. Additionally, interviewees were unable to articulate use of two of Passini's five wayfinding strategies when asked to recall their prior wayfinding experiences. Ascertaining people's thought processes through research is a challenge. A researcher has to either assume that visible behaviors indicate cognitive processes or ask people to verbalize those cognitive processes. When asked to verbalize thoughts, people often struggle to recall and clearly articulate how they were thinking during prior experiences. A method for addressing this challenge in wayfinding research has been the use of experiments where participants are given wayfinding tasks to complete and asked to think aloud while completing those tasks. This method allows people to articulate their thoughts as they occur, rather than having to recall them at a later date, and it minimizes the need for researchers to assume behaviors indicate thought processes. While used often in research set at hospitals and airports, the think aloud protocol is only now gaining use as a research method for investigations of library wayfinding behavior.

\section{Problem Statement}

Libraries can be large, complicated structures with multiple levels, annexes, and hidden corners, among other wayfinding challenges. These types of buildings can be difficult to navigate on their own. When library patrons are wayfinding, they may also have anxiety and information needs adding to their cognitive load, making wayfinding extremely difficult. The goal of wayfinding research in general is to ease orientation and navigation for humans wayfinding in a space. For libraries, this has led the majority of library wayfinding research to be guided by practical need to design libraries and signage systems that support user navigation through physical space, but in one specific library at a time. Very little research has been done that is based in theory or that aims to develop a working theory of library user wayfinding, thus limiting the generalizability of that research. A prior study began the process of testing applicability of a wayfinding theory to library patron wayfinding by investigating whether library patrons were making any use of Passini's wayfinding strategies (Mandel, 2013), but the study was inconclusive due to the use of unobtrusive observation and interviews, neither of which were able to capture patron's thoughts during wayfinding activities. Empirical research on wayfinding in libraries that is grounded in theory offers the chance to generalize findings beyond one library and its users to instead describe how users orient and navigate in libraries in general. This can 
help us meet users' needs with regard to where they need wayfinding information, what types of wayfinding information they need in which places, and where they are being overwhelmed with too much information, impeding their wayfinding ability.

This study contributes to the growth of theory-based wayfinding research in libraries by conducting an experiment using the think aloud protocol. The goal is to elucidate use of Passini's wayfinding strategies among public library users in order to determine if the strategies are used and if so, which ones are used and to what degree. The larger goal is to use these findings to develop guidelines for improving the level of wayfinding ease in libraries based on users' wayfinding behavior and spatial information needs. For example, if there are tasks for which users are not using signs to help them or areas of the library in which users know where to go based on architectural cues, then it's possible there are extraneous signs in the library that could be removed to lighten the cognitive load on users. This will users more likely to find what they are looking for in libraries, thereby increasing their satisfaction with the experience and likelihood they will continue to use libraries.

This research investigates three research questions:

RQ 1. If users are given a wayfinding task to complete in a facility and asked to think aloud while completing the task, which (if any) of Passini's strategies do they use to complete the task?

RQ 2. To what degree does the type of task affect which of the strategies wayfinders use?

RQ 3. If the strategies are explained to wayfinders, to what degree a) do they understand what the styles and strategies mean and b) realize whether or not not they are using the strategies while they wayfind?

\section{Literature review}

\subsection{Theoretical underpinnings of library wayfinding research}

A genesis of wayfinding research can be traced to The Image of the City (Lynch, 1960) and its appraisal of the external built environments intrinsic to cities. Lynch perceives the relationship between the city and any person (the user) in that environment as subject to a variety of "legibility." As wayfinding research turned to internal built environments (see Best's 1970 exploration of wayfinding in a constructed facility, the Town Hall in Manchester, UK), the research naturally became prescriptive. 
Understanding how individuals navigate built environments can inform architects, designers, and stakeholders about how to design facilities. Wayfinding research has found application for the design of large multi-use public buildings and systems such as housing complexes (Gärling, Lindberg, \& Mantyla, 1983) and museums (Cosley et al., 2009). Libraries, mostly public and academic, have also considered the need for and result from wayfinding research. This has contributed to the conversation, with an emphasis on library signage systems (Bosman \& Rusinek, 1997; Brown, 2002; Byam, 1979; Daniels \& Eakin, 1979; Loomis \& Parsons, 1979; Pollet \& Haskell, 1979; Schoonover \& Kinsley, 2014; Stempler \& Polger, 2013). Greater ease for users demands a more intuitive experience, one that frees them from dependence on even well placed signs. Research informed by Passini's conceptual framework of wayfinding (1981), the development of that framework, and its application in thoughtful, creative, and informed experiments has the potential to change facility design such that "users do not have to concentrate on navigation, but can orient and navigate intuitively while satisfying their needs" (Mandel, 2018, p. 3). The wayfinding described in Passini's 1981 conceptual framework has theoretical linkage to information seeking theory (Kuhlthau, 1993; Kuhlthau, Heinström, \& Todd, 2008); and it assumes an intended destination. Passini describes wayfinding in a built environment to include three synchronous processes: the user processing information with reference to previous and held knowledge/experience, making decisions and plans based on that knowledge, and transforming plans into actions. The conceptualized framework (Arthur \& Passini, 1992) is understood and used as a wayfinding information system - specifically as it facilitates success navigating to a desired location or piece of information. It is yet to be determined with any certainty whether the methodology can apply when a destination is not intended.

Discoverability in the physical and digital worlds is central to librarianship. With a focus on digital, as opposed to physical, wayfinding, Morville's Ambient Findability (2005) describes an iterative, step-by-step process through which people navigate individually. Given that each step is contingent upon previous decisions, the more precise an understanding of the thinking at each of those pressure points, the more informed and robust the data. There is a strong connection between Morville's emphasis on the iterative nature of searching and the value of think aloud protocol in research that examines how people find things. 
Baskaya, Wilson, and Özcan (2004) emphasize familiarity with the setting to explore ease and unease with navigation of built environments, as do Gärling et al. (1983). Bosman and Rusinek (1997), Li and Klippel (2012), and Corlett, Manenica, and Bishop (1972) investigate and describe the effectiveness of signage as an aid to navigation with implicit and explicit recommendations. Others look more broadly at facility and service systems (Dempsey, 2006, Evans, Fellows, Zorn, \& Doty, 1980, Hahn \& Zitron, 2011, Hassanain \& Mudhei, 2006, Palmer, 2008).

So, the exploration and research around wayfinding in libraries includes the influences of and on spatial design, the impact of signage, and other built directives. However, if the goals are to combat lostness (Best, 1970) and "improve the overall findability of library information and resources," (Mandel, 2018, p. 2) the research needs to describe the user experience as authentically as possible.

\subsection{Wayfinding research using the think aloud protocol}

One way to achieve an unfiltered account of the user experience is to employ think aloud protocol for collecting data. In this protocol, research participants are usually given a task to complete, then asked to articulate "what they saw, thought and did" while completing the task (Chebat, Gélinas-Chebat, \& Therrien, 2005, p. 1594). They are often audio-recorded, with their thoughts later transcribed for analysis.

Facilitators in Baker, Bakkalbasi, Call, and Kamsler's (2015) study prompted participants to "narrate their actions completely" (p. 2). Hahn and Morales (2011) employed a similar think aloud protocol and identified six thematic areas from participants' spoken thoughts. Discerning the "personal and affective" (p. 420) allowed researchers to know, assess, and evaluate a user's confidence as well as their level of discouragement. That kind of information supports the creation of design that is responsive to user feedback, understands the origins of the feedback, and incorporates user consultation in the creation of services. Kato and Takeuchi (2003) also advocate for the enriching role of taxonomies created from collected verbal data and the details proffered by think aloud transcripts.

Kinsley, Schoonover, and Spitler (2016) use Go/Pro cameras and think aloud protocol in conjunction with survey and mapping to help pinpoint wayfinding trouble spots in an academic library. Consciously building on the work of Larsen and Tatarka (2008) and Hahn and Zitron 
(2011), Kinsley et al. (2016) describe a cost effective, multi-method approach to identify specific decision and failure points in library wayfinding.

Larsen and Tatarka (2008) ask participants to think aloud in a study investigating the efficacy of the implementation of recommendations resulting from a prior wayfinding study. They categorize and rank data collected using think aloud protocol, with the protocol as valuable as any conclusion for their institution. They surmise that the user's unfiltered voice gives an "accurate representation of events" (p.68), richer reporting vis-a-vis quotations from the field, and clarification of murky or biased observations.

Schoonover and Kinsley (2014) comment that only an empathetic approach would reflect what participants think and feel at pivotal wayfaring decision making moments. They suggest think aloud protocol as the best way to achieve that. Mandel (2013) also recommends incorporating think aloud methodology to better understand participants' thoughts as those thoughts occur. Specifically, Mandel $(2013,2018)$ suggests that future studies using think aloud protocol could illuminate whether or not participants use Passini's wayfinding strategies as they wayfind, and if they do use Passini's strategies, which of the strategies they are using. Larson and Tatarka (2008) conclude that insight into patrons' thinking collected using think aloud protocol is a promising and, in fact, proven way to solve navigation and wayfinding problems by capturing user perspectives.

\section{Research design}

An experiment was conducted in a Rhode Island public library facility using 24 participants recruited from within the library, the local community college, and the listserv of a library and information science (LIS) academic program. The purpose of recruiting from the community college was to recruit participants who were not regular users of the library so the researcher could control for users' prior experience with the facility, and using the LIS listserv also proved effective for this. This resulted in a purposive sample consisting of 13 participants who had visited the library facility prior to the experiment and 11 who had not. These 24 participants were divided into three groups: control group $(\mathrm{CG})$, which received no explanation of Passini's strategies, experimental group one (EG1), which received explanation of the strategies using Passini's terminology, and experimental group two (EG2), which received explanation of the strategies using layman's terminology. Stratified random sampling was used 
to ensure that each group contained participants both familiar and unfamiliar with the facility (Table 1).

Table 1: Stratified Random Sample Used in Experiment

\begin{tabular}{lll}
\hline Group & Familiar with facility & Unfamiliar with facility \\
\hline CG $(n=9)$ & $n=5$ & $n=4$ \\
EG1 $(n=8)$ & $n=4$ & $n=4$ \\
EG1 $(n=7)$ & $n=4$ & $n=3$ \\
\hline
\end{tabular}

\subsection{Research protocol}

Each group was assigned three wayfinding tasks to complete in the library: task 1, general task to locate the children's department; task 2, multi-part task to locate a specific item from a section in the library (a novel by Stephen King that could be found in fiction, paperbacks, or large print); and task 3, a memory task to return to the entrance of the library from the location of the Stephen King novel. Participants received no external aids to searching beyond those already available in the facility. All participants were asked to think aloud as they completed the tasks, and their verbalizations were audio recorded for later content analysis using Passini's strategies as the coding scheme. Before completing the tasks, EG1 read a worksheet explaining Passini's strategies using Passini's terminology and EG2 read a worksheet explaining Passini's strategies using laymen's terminology; both groups were asked to refer to these explanations while thinking aloud during task completion. After completing the tasks, each participant completed a debriefing interview where s/he was asked about use of Passini's strategies. All participants signed a consent form prior to participating in the research and received $\$ 50$ for completing the experiment.

\subsection{Data analysis}

The recordings of participants thinking aloud during the experiment were transcribed, then interview notes, think aloud transcripts, and observer notes were all coded using Passini's strategies as a guide (Figure 1). Two researchers each coded the entire data set independently by first coding the documents in Word, then tabulating results in Excel. For each researcher, a summary sheet was tabulated to determine the strategies used by each participant during think aloud, observation, and interview, as well as a set of overview data to show all strategies used by 
each participant and strategies used by task. Then Krippendorff's alpha $(\alpha)$ was calculated on a random sample of the data to determine inter-coder reliability with result $\alpha=0.89$ (Krippendorff, 2004).

Once an acceptable level of reliability was determined, data were cleaned and imported into SPSS for analysis. For RQ 1 and RQ2, descriptive statistics were used to calculate frequencies. For RQ3, Pearson's $r$ was used to determine whether any relationship exists between group and reported use of strategies during the think aloud protocol and the interviews.

Figure 1. Coding Worksheet

\begin{tabular}{|c|c|c|c|c|c|c|c|c|}
\hline \multirow{2}{*}{ Main codes } & \multirow{2}{*}{ Detailed subcodes } & \multicolumn{2}{|c|}{ Transcript } & \multicolumn{2}{|c|}{ Observer Notes } & \multicolumn{2}{|c|}{ Interview } & \multirow{2}{*}{ Comments } \\
\hline & & Yes & No & Yes & No & Yes & No & \\
\hline Strategy 1 & $\begin{array}{l}\text { break problem into parts } \\
\text { while keeping larger task in } \\
\text { mind }\end{array}$ & & & & & & & \\
\hline Strategy 2 & narrow to smaller subtask & & & & & & & \\
\hline Strategy 3 & adapt to unforeseen problems & & & & & & & \\
\hline Strategy 4 & access schemata & & & & & & & \\
\hline Strategy 5 & $\begin{array}{l}\text { gather and respond to } \\
\text { environmental information }\end{array}$ & & & & & & & \\
\hline \multicolumn{9}{|c|}{ More details on strategies } \\
\hline \multicolumn{9}{|c|}{1 Instead of thinking about how to complete the whole task you have been given, you think about the steps you will need to take in order to find the object. } \\
\hline & \multicolumn{8}{|c|}{2 As you are looking for the object you have been assigned, you focus on one specific step at a time. } \\
\hline & \multicolumn{8}{|c|}{$\begin{array}{l}\text { While you are walking around the library looking for the object you have been assigned, you run into problems and in order to figure out how to get back } \\
\text { on track, you look around the library to figure out where you need to go. }\end{array}$} \\
\hline & \multicolumn{8}{|c|}{$\begin{array}{l}\text { In order to find the object you have been assigned, you think about previous visits to a library or bookstore, remember how things are usually arranged, } \\
\text { then start looking for your assigned object. }\end{array}$} \\
\hline & \multicolumn{8}{|c|}{$\begin{array}{l}\text { Before you being looking for your assigned object, you look around the library to collect information about where things are in the library. Then, you } \\
\text { think about all that information while you figure out how to find the object. }\end{array}$} \\
\hline
\end{tabular}

\section{Findings}

\subsection{Strategies}

The first RQ asks which, if any, strategies participants would use while completing wayfinding tasks. Participants utilized all five strategies during the completion of the experiment (Table 2). Participants mentioned use of all five strategies while thinking aloud and in the debriefing interviews, and the researcher observed participants to use all five strategies while they completed the wayfinding tasks.

Table 2: Recorded or Observed Use of Strategies by Method of Data Collection

\begin{tabular}{ccccccccccc}
\hline & \multicolumn{2}{c}{ Strategy 1 } & \multicolumn{2}{c}{ Strategy 2 } & \multicolumn{2}{c}{ Strategy 3 } & \multicolumn{2}{c}{ Strategy 4 } & \multicolumn{2}{c}{ Strategy 5 } \\
\cline { 2 - 11 } & $\mathrm{n}$ & $\%$ & $\mathrm{n}$ & $\%$ & $\mathrm{n}$ & $\%$ & $\mathrm{n}$ & $\%$ & $\mathrm{n}$ & $\%$ \\
\hline Think aloud & 8 & 33.3 & 9 & 37.5 & 9 & 37.5 & 14 & 58.3 & 23 & 95.8
\end{tabular}




\begin{tabular}{lllllllllll}
$\begin{array}{l}\text { Researcher } \\
\text { observation }\end{array}$ & 3 & 12.5 & 5 & 20.8 & 10 & 41.7 & 16 & 66.7 & 24 & 100.0 \\
$\begin{array}{l}\text { De-briefing } \\
\text { interview }\end{array}$ & 7 & 29.2 & 9 & 37.5 & 10 & 41.7 & 20 & 83.3 & 24 & 100.0 \\
\hline
\end{tabular}

Overall use of strategies was calculated for each case by noting use of the strategy collected from any of the three methods (Figure 2). The most frequently used strategy was strategy $5(n=24)$, with strategy 4 a close second $(n=22)$. The next most frequently used strategy was strategy $2(n=15)$, with strategies 1 and 3 used least often $(n=12$ and $n=13$, respectively).

Figure 2. Strategies Used (Overall)

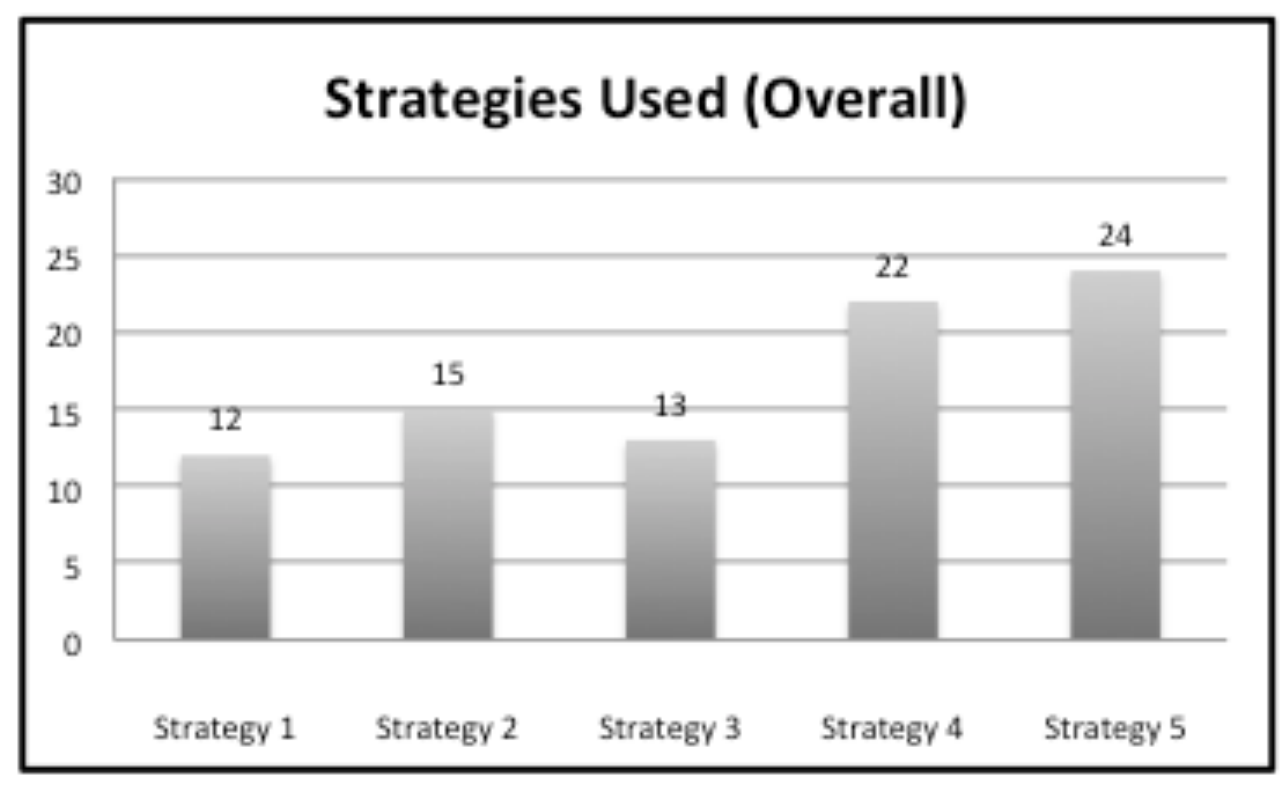

\subsection{Effect of task type}

The second RQ asks whether the type of task affects use of the strategies (Table 3). For task 1 (general: locate the children's department), participants used only strategy $4(n=2)$ and strategy $5(n=23)$. For task 2 (multi-part: find a novel by Stephen King), participants used all five strategies. Strategies 4 and 5 were the most frequently used ( $n=18$ and $n=24$, respectively), but the other three strategies were all used to some degree (strategy $1, n=9$; 
strategy $2, n=10$; strategy $3, n=11)$. For task 3 , participants used only strategies $4(n=3)$ and 5 $(n=15)$. For task 3 , some participants did not indicate use of any strategy at all $(n=3)$.

Table 3: Use of Strategies by Task

\begin{tabular}{lrrrrrrrrrr}
\hline & \multicolumn{2}{c}{ Strategy 1} & \multicolumn{2}{c}{ Strategy 2} & \multicolumn{2}{c}{ Strategy 3 } & \multicolumn{2}{c}{ Strategy 4 } & \multicolumn{2}{c}{ Strategy 5 } \\
\cline { 2 - 11 } & $\mathrm{n}$ & \multicolumn{1}{c}{$\%$} & \multicolumn{1}{c}{$\mathrm{n}$} & \multicolumn{1}{c}{$\%$} & \multicolumn{1}{c}{$\mathrm{n}$} & \multicolumn{1}{c}{$\%$} & \multicolumn{1}{c}{$\mathrm{n}$} & \multicolumn{1}{c}{$\%$} & $\mathrm{n}$ & \multicolumn{1}{c}{$\%$} \\
\hline Task 1 & 0 & 0.0 & 0 & 0.0 & 0 & 0.0 & 2 & 8.3 & 23 & 95.8 \\
Task 2 & 9 & 37.5 & 10 & 41.7 & 11 & 45.8 & 18 & 75.0 & 24 & 100.0 \\
Task 3 & 0 & 0.0 & 0 & 0.0 & 0 & 0.0 & 3 & 12.5 & 15 & 62.5 \\
\hline
\end{tabular}

\subsection{Effect of explaining the strategies}

The third RQ explores whether explanation of the strategies affects users' awareness of their use during completion of wayfinding tasks. This experiment included three groups, only two of which received explanation of Passini's strategies prior to task completion: EG1, explanation of Passini's strategies in his terminology, and EG2, explanation of Passini's strategies in laymen's terms. Members of all three groups used all five strategies over the entire experiment.

Table 4 shows the similarity in reported use of strategies via think aloud across all three groups. Testing for correlation in SPSS yielded no significant correlation between group and reported use of strategy $1(r=.181)$, strategy $4(r=-.191)$, or strategy $5(r=-.021)$. There was weak positive correlation between group and reported use of strategy $2(r=.397)$ and moderate negative correlation between group and reported use of strategy $3(r=-.450, p>.05)$.

Table 4: Reported Use of Strategy in Think Aloud Recordings by Group

\begin{tabular}{|c|c|c|c|c|c|c|c|c|c|c|}
\hline & \multicolumn{2}{|c|}{ Strategy 1} & \multicolumn{2}{|c|}{ Strategy 2} & \multicolumn{2}{|c|}{ Strategy 3} & \multicolumn{2}{|c|}{ Strategy 4} & \multicolumn{2}{|c|}{ Strategy 5} \\
\hline & $\mathrm{n}$ & $\%$ & $\mathrm{n}$ & $\%$ & $\mathrm{n}$ & $\%$ & $\mathrm{n}$ & $\%$ & $\mathrm{n}$ & $\%$ \\
\hline $\begin{array}{l}\text { CG } \\
\text { EG }\end{array}$ & 3 & 33.3 & 1 & 11.1 & 5 & 55.6 & 6 & 66.7 & 9 & 100.0 \\
\hline $\begin{array}{l}1 \\
\mathrm{EG}\end{array}$ & 1 & 12.5 & 4 & 50.0 & 4 & 50.0 & 5 & 62.5 & 7 & 87.5 \\
\hline 2 & $\begin{array}{l}4 \\
r=\end{array}$ & 57.1 & $\begin{array}{l}4 \\
r=\end{array}$ & 57.1 & $\begin{array}{l}0 \\
r=\end{array}$ & $0^{0.0}$ & $\begin{array}{l}3 \\
r=\end{array}$ & $\begin{array}{l}42.9 \\
1\end{array}$ & $\begin{array}{l}7 \\
r=\end{array}$ & $\begin{array}{l}100.0 \\
1\end{array}$ \\
\hline
\end{tabular}

* significant at the 0.05 level 
Table 5 shows the similarity in reported use of strategies via de-briefing interviews across all three groups. Testing for correlation in SPSS yielded no significant correlation between group and reported use of any strategy (strategy 1, $r=-.160$; strategy $2, r=.079$; strategy $3, r=-.225$; strategy $4, r=.092$. In the case of strategy $5, r$ could not be calculated because all participants reported use of strategy 5 via the debriefing interview making the variable constant).

Table 5: Reported Use of Strategy in Interviews by Group

\begin{tabular}{|c|c|c|c|c|c|c|c|c|c|c|}
\hline & \multicolumn{2}{|c|}{ Strategy 1} & \multicolumn{2}{|c|}{ Strategy 2} & \multicolumn{2}{|c|}{ Strategy 3} & \multicolumn{2}{|c|}{ Strategy 4} & \multicolumn{2}{|c|}{ Strategy 5} \\
\hline & $\mathrm{n}$ & $\%$ & $\mathrm{n}$ & $\%$ & $\mathrm{n}$ & $\%$ & $\mathrm{n}$ & $\%$ & $\mathrm{n}$ & $\%$ \\
\hline $\begin{array}{l}\text { CG } \\
\text { EG }\end{array}$ & 4 & 44.4 & 3 & 33.3 & 4 & 44.4 & 7 & 77.8 & 9 & 100.0 \\
\hline $\begin{array}{l}1 \\
\mathrm{EG}\end{array}$ & 1 & 12.5 & 3 & 37.5 & 5 & 62.5 & 7 & 87.5 & 8 & 100.0 \\
\hline 2 & $\begin{array}{l}2 \\
r=\end{array}$ & $0^{28.6}$ & $\begin{array}{l}3 \\
r=\end{array}$ & 42.9 & $\begin{array}{l}1 \\
r=\end{array}$ & $5^{14.3}$ & $\begin{array}{l}6 \\
r=\end{array}$ & 85.7 & $\begin{array}{l}7 \\
r^{*}\end{array}$ & 100.0 \\
\hline
\end{tabular}

* $r$ cannot be computed because the strategy use variable is constant

\section{Discussion}

\subsection{Use of Passini's five wayfinding strategies}

In a previous study (Mandel, 2013), strategies 1 and 2 were not observed or mentioned at all. This experiment suggests that public library users are employing these strategies, although to a lesser degree than strategies 4 and 5. Both strategies 1 and 2 explain how a wayfinder parses the wayfinding problem into smaller parts in order to focus on one part of the wayfinding task at a time. This experiment asked people to complete three tasks; two of these were one-part tasks that asked people to find the children's department (task 1) and then to return to the entrance (task 3). None of the participants used strategies 1 or 2 (or strategy 3 ) to complete either task 1 or task 3. Further research should employ a wider array of tasks, with more tasks involving multiple steps to test whether library patrons do use strategies 1 and 2 when faced with a more complicated wayfinding task than locating one department or returning to the entrance.

As it stands now, wayfinding research in libraries is often driven by researcher-contrived tasks. Research is also necessary to determine the actual tasks patrons are completing in libraries: are they primarily engaging in single step tasks or multi-step tasks? If they are primarily engaging in single-step tasks, that would suggest that libraries should focus on signage that emphasizes high-level information such as names of departments (e.g., Children's or Adults) or 
sections of the library (e.g., Biographies or Fiction) and minimize signage that goes into deeper levels of information. If patrons are undertaking a larger percentage of multi-step tasks, then library signage needs to include higher-level information that helps people find first a department or section and more detailed information to locate specific sections within a department (e.g., easy readers in the children's department or mysteries in the adult fiction department).

In the prior study, the strategy mentioned most often by interviewees was strategy 3 (Mandel, 2018), which was one of the least used strategies in this study. The use of strategy 3 may be more dependent on facility complexity than other strategies. The facility used in this study has one floor and the facility used in the prior study has two floors that can be accessed via two sets of stairs and an elevator. Wayfinders only need to adapt and respond when they encounter a problem with orientation or navigation; if no problems are encountered, there is nothing to which to adapt and respond. It is possible that problems are encountered less often in a smaller, one-story library than in a two-story one. Since patrons in both studies used this strategy, it should still be considered as a theory of library user wayfinding behavior is developed. Future research could compare user wayfinding in single-story and multi-story facilities to determine whether the same users employ strategy 3 in a multi-story library but not in a single-story library.

In the general and memory tasks, participants used only strategies 4 and 5 . In the multipart task, participants used all five strategies, although strategies 4 and 5 were still used more heavily than strategies 1, 2, and 3. Patrons in the prior study also used strategies 4 and 5 (Mandel, 2013). Every participant used strategy 5 during the experiment, and all but one $(n=23)$ used strategy 5 for task 1 . As patrons in both studies relied on strategies 4 and 5 , these may present the highest potential for applying Passini's conceptual framework (1981) to understanding library user wayfinding behavior. The most common form of strategy 5 use was looking around for signs. When asked in the debriefing interview what they did most often to solve the given wayfinding tasks, the most common answer was that they looked for signs. Despite Arthur and Passini's argument that signage cannot overcome a facility poorly designed for wayfinding (1992), it seems to be something that library patrons often use to help them navigate library facilities. This may explain the multitude of signage guidebooks and perhaps also lends support to the call for a signage formula (Mandel \& Johnston, 2017). Such a formula would allow librarians to "assess the appropriate number and types of signage for their libraries 
based on the factors that make each library unique, the facility and the users" (p. 10). This would help librarians avoid the information overload that comes from having too many signs while distributing the types of signs that help guide users as they orient and navigate the library facility.

\subsection{Limited effect of the intervention}

There is minimal correlation between group and reported use of strategy via think aloud and a complete lack of correlation between group and reported use of strategy via interview (See Tables 4 and 5 above). This indicates that the data do not support the proposition that explaining the strategies to wayfinders has much significant impact on their realization they are using the different strategies while they wayfind. Based on this, future experiments should focus on different interventions.

Something that might be more effective would be testing the use of different strategies in different types of wayfinding tasks. This study found use of a wider array of strategies in the most complicated of the three wayfinding tasks, so use of a wider variety of tasks, and tasks that require more steps might help tease out more details on when and to what degree library wayfinders are using the strategies to guide their wayfinding in a library facility.

Other interventions that could be tested include:

- User-generated tasks: What are the actual tasks users attempt to complete in libraries and which strategies are used for which tasks? A study could begin by surveying or interviewing users in a library about the tasks they had completed that day and how they had completed those tasks. Those tasks could then be used in an experiment in which subjects are asked to complete the user-generated tasks to see which, if any, strategies are employed in the completion of the tasks. This could be compared to how the user who generated the task completed the task to see if there are any differences in wayfinding strategies when the subject designs their own tasks versus being assigned someone else's task.

- Different facilities: Does building complexity affect the use of Passini's strategies, particularly strategy 3 ? An experiment could ask subjects to conduct the same tasks in two different libraries, one a single-story library and the other a multi-story library, to determine whether users employ different or the same strategies to complete the same tasks in the different library facilities. 
- Quantity and type of signs: How does the density of signs (number of signs per square foot) affect user wayfinding and how does the ratio of types of signs (informational, directional, and regulatory) affect user wayfinding? A section of a library could be designated for an experiment, varying the number of signs and ratio of types of signs as the intervention in task completion.

\subsection{Limitations}

This research is one small experiment, conducted in one public library facility. Additional research is required to determine any generalizability of the results beyond the participants in this one study and to other library facilities and other library types.

\section{Conclusion}

This research indicates users are primarily wayfinding based on their prior experience with or knowledge of library facilities and how to navigate them (strategy 4) and by collecting and using information along the way (strategy 5). They are using Passini's other strategies, but to a lesser extent. The question then becomes, how can we make it easier for users to navigate using the strategies they rely on? If users are basing their wayfinding on their prior experience with navigating similar structures, we should help them do that by designing and organizing library facilities in ways that mirror users' schemata. Library users are relying on signage when they use strategy 5, which supports the strong focus on the library literature on signage. Which signs they are using and which are not helping them is something that needs to be considered. If there are signs that aren't helping users orient themselves or navigate in library facilities, we need to ask ourselves why we have those signs and why we don't remove them to reduce users' cognitive load.

Through participant articulation during the think aloud protocol and immediate debriefing interview, it is clear that library wayfinders are using all five of Passini's strategies as they wayfind in library facilities. Whether people are told about the strategies beforehand or not, they are using them. Greater understanding about how library users wayfind can lead to the development of a theory of library user wayfinding that explains how library users orient and navigate in libraries. This might well be based on Passini's framework but it is likely to also take into consideration theories of information-seeking behavior. The ultimate goal is for the theory to be translated into understandable action steps that libraries can take to redesign facilities and implement new signage and other wayfinding tools that improve the library experience for our 
patrons. A theoretical framework that describes user wayfinding behavior of all types of library users can lead to library design and signage guidelines based on generalizable, empirical data.

Much work remains to be done to understand library user wayfinding behavior, and this study suggests that experimental methods that ask users to complete wayfinding tasks while thinking aloud might be the most effective method to undertake such research. This needs to occur in all types of library facilities using all types of users, that is, people of all ages, educational attainment levels, experience with the facility, etc. The bottom line is that to really help users orient and navigate in library facilities, we need to have a more informed understanding of what they're thinking and doing as they are wayfinding in all types of libraries (public, academic, school, and special and single- and multi-story).

\section{Acknowledgements}

This work was supported by a University of Rhode Island CFR Career Enhancement Award. The researchers also wish to acknowledge the generous support of the Cranston Public Library and specifically, the director, for allowing use of the main library as the research site.

\section{References}

Arthur, P., \& Passini, R. (1992). Wayfinding: People, signs, and architecture. New York, NY: McGraw-Hill.

Baker, M., Bakkalbasi, N., Call, E., \& Kamsler, B. (2015). Burke Library wayfinding study report. New York, NY: Columbia University. Retrieved from http://dx.doi.org/10.7916/D8KH0MG6

Baskaya, A., Wilson, C., \& Özcan, Y. (2004). Wayfinding in an unfamiliar environment: Different spatial settings of two polyclinics. Environment and Behavior, 36(6), 839-867.

Best, G. (1970). Direction-finding in large buildings. In D.V. Canter (Ed.), Architectural psychology: Proceedings of the conference held at Dalandhui University of Strathclyde, 28 February - 2 March 1969 (pp. 72-75). Cambridge, UK: W. Heffer and Sons.

Bosman, E., \& Rusinek, C. (1997). Creating the user-friendly library by evaluating patron perceptions of signage. Reference Services Review, 25(1), 71-82.

Brown, C. R. (2002). Interior design for libraries: Drawing on function and appeal. Chicago, IL: American Library Association.

Byam, M. S. (1979). An approach to public library signage. In D. Pollet \& P. C. Haskell (Eds.), Sign systems for libraries (pp. 137-144). New York, NY: R. R. Bowker. 
Chebat, J.-C., Gélinas-Chebat, C, \& Therrien, K. (2005). Lost in a mall, the effects of gender, familiarity with the shopping mall and the shopping values on shoppers' way finding processes. Journal of Business Research, 58(11), 1590-1598. doi:10.1016/j.jbusres.2004.02.006

Corlett, E. N., Manenica, I., \& Bishop, R. P. (1972). The design of direction finding systems in buildings. Applied Ergonomics, 3(2), 66-69.

Cosley, D., Baxter, J., Lee, S., Alson, B., Nomura, S., Adams, P., . . Gay, G. (2009). A tag in the hand: Supporting semantic, social, and spatial navigation in museums. Proceedings of the Annual CHI Conference on Human Factors in Computing Systems, 27, 1953-1962. doi:10.1145/1518701.1518999

Daniels, B., \& Eakin, G. (1979). Coordinating graphics and architecture. In D. Pollet \& P. C. Haskell (Eds.), Sign systems for libraries (pp. 181-185). New York, NY: R. R. Bowker.

Dempsey, B. (2006). Wayfinding in action: Patrons get to what they want fast at these four libraries. Library Journal, 131(9), 14-15.

Evans, G. W., Fellows, J., Zorn, M., \& Doty, K. (1980). Cognitive mapping and architecture. Journal of Applied Psychology, 65(4), 474-478.

Gärling, T., Lindberg, E., \& Mantyla, T. (1983). Orientation in buildings: Effects of familiarity, visual access, and orientation aids. Journal of Applied Psychology, 68(1), 177-186.

Hahn, J., \& Morales, A. (2011). Rapid prototyping a collections-based mobile wayfinding application. Journal of Academic Librarianship, 37, 416-422.

doi:10.1016/j.acalib.2011.06.001

Hahn, J., \& Zitron, L. (2011). How first-year students navigate the stacks: Implications for improving wayfinding. Reference \& User Services Quarterly, 51(1), 28-35.

Hassanain, M. A., \& Mudhei, A. A. (2006). Post-occupancy evaluation of academic and research library facilities. Structural Survey, 24(3), 230-239.

Kato, Y., \& Takeuchi, Y. (2003). Individual differences in wayfinding strategies. Journal of Environmental Psychology, 23(2), 171-188. doi:10.1016/S0272-4944(03)00011-2

Kinsley, K. M., Schoonover, D., \& Spitler, J. (2016). GoPro as an ethnographic tool: A wayfinding study in an academic library. Journal of Access Services, 13(1), 7-23. doi:10.1080/15367967.2016.1154465 
Krippendorff, K. (2004). Content analysis: An introduction to its methodology. Thousand Oaks, CA: Sage.

Kuhlthau, C. C. (1993). Seeking meaning: A process approach to library and information services. Norwood, NJ: Ablex.

Kuhlthau, C. C., Heinström, J., \& Todd, R. J. (2008). The 'information search process' revisited: Is the model still useful? Information Research, 13(4), paper 355. Retrieved from http://InformationR.net/ir/13-4/paper355.html

Larsen, D., \& Tatarka, A. (2008). Wayfinding revisited: Improved techniques for assessing and solving usability problems in physical spaces. In S. Hiller, K. Justh, M. Kyrillidou, \& J. Self (Eds.), Building effective, sustainable, practical assessment: Proceedings of the 2008 Library Assessment Conference, August 4-7, 2008, Seattle, Washington (pp. 65-73). Washington, DC: Association of Research Libraries.

Li, R., \& Klippel, A. (2012). Wayfinding in libraries: Can problems be predicted? Journal of Map and Geography Libraries: Advances in Geospatial Information, Collections and Archives, 8(1), 21-38. doi:10.1080/15420353.2011.622456

Loomis, R. J., \& Parsons, M. B. (1979). Orientation needs and the library setting. In D. Pollet \& P. C. Haskell (Eds.), Sign systems for libraries (pp. 3-15). New York, NY: R. R. Bowker.

Lynch, K. (1960). The image of the city. Cambridge, MA: Massachusetts Institute of Technology.

Mandel, L. H. (2013). Finding their way: How public library users wayfind. Library and Information Science Research, 35(4), 264-271. doi:10.1016/j.lisr.2013.04.003

Mandel, L. H. (2018). Understanding and describing users' wayfinding behavior in public library facilities. Journal of Librarianship and Information Science, 50(1), 23-22. doi:10.1177/0961000616635243

Mandel, L. H., \& Johnston, M. P. (2017). Evaluating library signage: A systematic method for conducting a library signage inventory. Journal of Librarianship and Information Science, OnlineFirst. doi:10.1177/0961000616681837

Morville, P. (2005). Ambient findability. Sebastopol, CA: O’Reilly. Retrieved from http://proquestcombo.safaribooksonline.com.uri.idm.oclc.org/0596007655

Palmer, S. S. (2008). In our visitors' footsteps: Using a "visitor experience" project to assess services and facilities at the Library of Virginia. In S. Hiller, K. Justh, M. Kyrillidou, \& J. 
Self (Eds.), Building effective, sustainable, practical assessment: Proceedings of the 2008 Library Assessment Conference, August 4-7, 2008, Seattle, Washington (pp. 8594). Washington, DC: Association of Research Libraries.

Passini, R. (1981). Wayfinding: A conceptual framework. Urban Ecology, 5, 17-31.

Pollet, D., \& Haskell, P. C. (1979). Introduction. In D. Pollet \& P. C. Haskell (Eds.), Sign systems for libraries (pp. ix-xii). New York, NY: R. R. Bowker.

Schoonover, D., \& Kinsley, K. M. (2014). Stories from the stacks: Students lost in the labyrinth. Journal of Access Services, 11(3), 175-188. doi:10.1080/15367967.2014.914426

Stempler, A. F., \& Polger, M. A. (2013). Do you see the signs? Evaluating language, branding, and design in a library signage audit. Public Services Quarterly, 9(2), 121-135. doi:10.1080/15228959.2013.785881 